\title{
RESENHA
}

\section{MIL VEZES MAIS JUSTO: O QUE AS PEÇAS DE SHAKESPEARE NOS ENSINAM SOBRE A JUSTIÇA}

\author{
LUANA RAMOS VIEIRA ${ }^{1}$ \\ Luiz Gonzaga Silva Adolfo²
}

\section{INTRODUÇÃO}

$\mathrm{O}$ autor, Kenji Yoshino, inicia a obra rememorando como surgiu a sua paixão pela união entre Direito e Literatura. Ainda na faculdade, decidiu escrever como esses dois grandes ramos se encontram e se relacionam tão perfeitamente. A ideia de abordar as obras do grande dramaturgo inglês foi o que deu origem ao livro Mil vezes mais justo: o que as peças de Shakespeare nos ensinam sobre a justiça.

Na sequência, elaboramos uma síntese das reflexões que Yoshino nos oferece ao analisar as principais obras do mais influente dramaturgo do
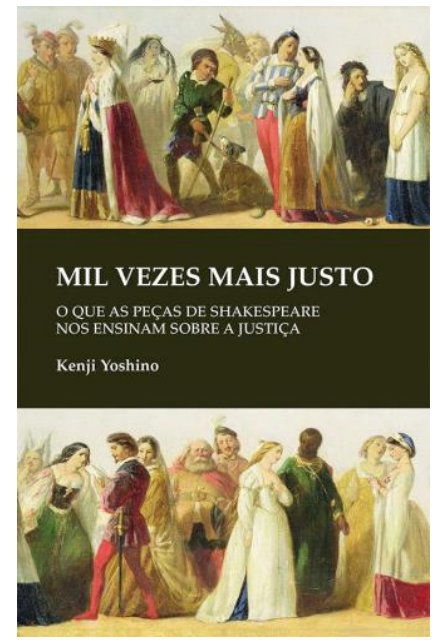

YOSHINO, Kenji. Mil vezes mais justo: o que as peças de Shakespeare nos ensinam sobre a justiça. São Paulo: mundo.

1 Graduanda em Direito (ULBRA). E-mail: luanavieira42@hotmail.com

2 Doutor em Direito (UNISINOS). Professor do Programa de Pós-Graduação em Direito da Universidade de Santa Cruz do Sul. Professor do Curso de Direito da Universidade Luterana do Brasil. E-mail: gonzagaadolfo@yahoo.com.br 


\section{O VINGADOR (TITO ANDRÔNICO)}

"Tito" foi considerada uma das peças mais sanguinárias de Shakespeare, na qual a maior parte dos personagens morre de forma violenta. Assim, a obra foi repudiada; todavia, Yoshino sustenta que, em verdade, se trata de uma forma de Shakespeare expressar a necessidade de existir um Estado de Direito. Naquela época, ou a pessoa acreditava em um Estado fraco, ou fazia justiça com as próprias mãos. Então, não se trata de simples violência, mas de "a vida como ela é", em um território onde o Estado não tinha força suficiente para trazer paz.

Por essa razão, entende-se que o objetivo do ensaio é justamente demonstrar a importância de se colocar "freios" (através das leis, do Estado de Direito), a fim de garantir a ordem. Yoshino oferece um breve resumo da obra, colacionando pequenos trechos. Logo após, relaciona a repulsa sentida pelo público diante das cenas de mutilação presentes na peça com as reações de seus alunos quando, em sala de aula, lhes mostra slides contendo imagens dos atentados de 11 setembro de 2001. Assim, Yoshino busca abordar como surgem os sentimentos de vingança privada e a necessidade de serem sumariamente coibidos. Nesta linha de mira, Tito Andrônico demonstra que devemos resistir aos nossos instintos para que essa vingança não nos destrua.

\section{O ADVOGADO (O MERCADOR DE VENEZA)}

A comédia d'O mercador é trazida para destacar que o Estado de Direito, por si só, não é suficiente para prevenir abusos de poder - já que ele próprio é capaz de cometê-los. Mesmo aqueles versados em Direito podem dele se utilizar para auferir vantagens indevidas. Yoshino destaca que essa obra de Shakespeare serve, precipuamente, para que seja reconhecida a importância do "governo das leis", e não a do "governo dos homens", pois no segundo sempre haverá mais discórdia do que harmonia. O primeiro, das leis, todavia, ainda que haja desentendimento e litígio, sempre oferecerá mais segurança.

Yoshino faz uma análise da peça apresentando-nos à Pórcia. Essa personagem representa uma "advogada" possuidora do dom da palavra, que se utiliza de todos os meios para atender aos seus propósitos. Nenhuma lei pode subjugá-la. Pórcia age na área limítrofe da lei (ali representada pelo 
testamento de seu pai), fazendo uso da retórica para auxiliar Bassânio a escolher o porta-joias correto, pois só assim poderá desposá-la. O mesmo ocorre em relação ao contrato da libra de carne humana, quando Pórcia distorce o contrato a fim de persuadir o credor de que o devedor tem direito a um cirurgião.

\section{O JUIZ (MEDIDA POR MEDIDA)}

Medida por medida possui, segundo Yoshino, três significados. O primeiro deles, que se relaciona ao cristianismo, põe em relevo que é preciso observar antes de tudo as próprias deficiências para, somente após, analisar a incapacidade alheia - ou seja, destaca o julgar com empatia. O segundo é o da ética de comensurabilidade do Velho Testamento, expresso na máxima "olho por olho, dente por dente" - se trata do julgar pela letra da lei. O terceiro, de matiz pagão, propõe julgar com a temperança de Aristóteles ou o meio-termo de Arquimedes.

A peça, por sua vez, invoca que nenhuma sociedade deva ser pautada pelos extremos, de julgar com empatia ou pela letra fria da lei - mas por um meio-termo, que seria o terceiro significado. Nesse sentido, é ressaltada a importância de se seguirem as regras sem, contudo, ser demasiadamente frio: é necessário que uma mediania seja encontrada, conciliando também a empatia. Para Yoshino, Shakespeare percebeu, portanto, que os juízes não podem se ater à pura empatia ou à mera lei, é preciso um equilíbrio, pois "o ato de julgar diz respeito ao grau de imparcialidade com que aplicamos regras gerais a circunstâncias particulares”(p. 96).

\section{O DESCOBRIDOR DE FATOS (OTELO)}

Otelo demonstra como funcionam as investigações. As pessoas que conduzem os fatos são conhecidas como "descobridores de fatos", e existem dois tipos de fatos: os sobrenaturais e os humanos. Nesse sentido, as pessoas esperam que juízes e jurados descubram a verdade dos fatos, desacreditando na busca sobrenatural. Confiamos cegamente, diante da falsa sensação de segurança que é transmitida por aqueles que, supostamente, "descobrem os fatos".

Otelo é um personagem de origem militar, que mata a esposa, Desdêmona, em razão de sua suposta infidelidade. Tal semente de discórdia 
foi plantada por Iago, que lhe entregou como "prova" o lenço dado por Otelo à noiva. Essa produção probatória é suficiente para desencadear um assassinato, em virtude da segurança de Otelo no julgamento de Iago. Trata-se de um clássico exemplo em que a prova "divina", sobrenatural, foi mais importante do que a prova humana. Yoshino ressalta que Shakespeare era cético quanto a deixarmos a prova divina de lado e que foi essa a razão pela qual escreveu a peça. Para Yoshino, o drama de Otelo serviria para nos alertar de que devemos nos ater em preservar a prova palpável e humana em detrimento da evidência divina, sobrenatural.

\section{O SOBERANO (A HENRÍADA)}

O personagem Hal, de "Henríada”, assume o trono após o falecimento de seu pai, Henrique IV - tornando-se Henrique V. Inicialmente, renega seu genitor biológico em detrimento de Falstaff, por quem nutre admiração. Após assumir o trono, procurado por Falstaff, renega-o, abraçando o antigo nêmesis Lorde Grande Juiz. Yoshino defende que Shakespeare antecipa o discurso de Max Weber sobre a necessidade de um líder trilhar seu caminho antes de estabelecer sua autoridade.

Primeiramente, existe a "autoridade feudal", exercida pelos patriarcas. Em segundo, a “autoridade carisma”, culto da personalidade que pode tanto ser exercido pelo governante eleito como pelo grande demagogo. E, em terceiro, há a "autoridade legal", aqui exercida pelo servidor do Estado. Shakespeare sugere, assim, que a verdadeira autoridade é uma combinação dessas três. Yoshino, por sua vez, defende que Hal demonstra uma admirável capacidade de circular entre as três facetas. A mensagem obtida é de que o poder supremo é basicamente impuro, e a sensação deixada por Shakespeare é de que o "governante justo talvez seja mais singular do que raro", bem como "mais irreal do que singular" (p. 172).

\section{NATUREZA (MACBETH)}

Macbeth é uma tragédia que acaba bem, afirma Yoshino, ressaltando ser possível reconhecer a crença em um universo autorregulado como “justiça natural”. Somos lembrados de que a justiça não constitui um fenômeno natural, mas sim de uma conquista humana deveras frágil. $\mathrm{Na}$ 
peça, a justiça humana e a justiça divina saem de cena, dando lugar exclusivamente à justiça natural.

Essa justiça natural, todavia, não poderá ser alcançada sem um impulso por parte dos seres humanos que a procuram. É natural que os indivíduos, preguiçosos, sentem-se e aguardem a justiça ocorrer naturalmente, devido à falácia de que a justiça natural "nunca falha". Todavia, é importante ter em mente que o "arco moral do universo" poderá e deverá inclinar-se para o lado da justiça, desde que conte com o auxílio das pessoas, cada qual fazendo a sua parte.

\section{O INTELECTUAL (HAMLET)}

Diferentemente dos demais personagens até aqui apresentados, Hamlet é um intelectual. Refugia-se na procrastinação de vingar a morte do seu pai buscando, precipuamente, não apenas a justiça, "mas a justiça ideal”, razão pela qual planeja tanto a vendetta.

As protelações de Hamlet fazem parte da busca por essa justiça perfeita. Inicialmente, protela para confirmar a culpa de Cláudio na eliminação de seu pai; depois, protela para garantir que tenha sido completamente vingado. Isso demonstra um inabalável compromisso com a forma ideal de justiça, refletindo, em verdade, força na sua determinação; em vez de fraqueza.

\section{O LOUCO (REI LEAR)}

O Rei Lear trata de um monarca que, após ter deixado o poder, sofre tão intensamente que atinge a loucura. É pitoresco falar em loucura quando buscamos compreender a justiça - entretanto, a primeira proporciona uma compreensão mais profunda não só da segunda, mas de seus limites. Abrindo mão da realidade, Lear torna-se capaz de perceber uma forma de justiça completamente purificada e, uma vez encontrada, nunca mais volta à lei dos mortais.

$\mathrm{Na}$ concepção de Yoshino, Lear renunciou à lei em benefício da justiça. A obra transmite, de forma inequívoca, a dura realidade, pois é ao lê-la que conseguimos pensar mais claramente em nossa própria morte que é o destino de todos. O truque final da peça, como se salienta, é que o Rei renunciou à justiça em prol do amor. Ao escapar da jurisdição da vida, 
"não escapamos apenas do império da lei, mas também do império da justiça” (p. 250). Nesse sentido, é dito que, uma vez no leito de morte, somente as pessoas infelizes pensam em justiça; pois as felizes, por outro lado, pensam no amor.

\section{O MAGO (A TEMPESTADE)}

A tempestade conta a história de Próspero, um governante que, devido à sua condição de mago, exerce maior influência sobre a sociedade do qualquer outro ser humano. Dizem que o poder tende a corromper; e o poder absoluto deteriora absolutamente. Todavia, essa não é a história aqui contada, pois Próspero abre mão do poder no último momento, demonstrando um comportamento ético. Em verdade, é possível dizer que, às vezes, a justiça não é sempre sobre exercer o poder de forma ininterrupta; mas, sim, de renunciar a ele.

Yoshino deixa claro que a alegoria aqui representada é bem ilustrada na maioria de nossos sistemas, nos quais o arranjo de "freios e contrapesos" foi o encontrado para que o egoísmo individual pudesse controlar a soberba alheia. O último e, talvez, esquecido significado da "tempestade" é aquele proveniente da arte da alquimia - cuja fervura, em alambique, transforma em ouro puro substâncias outrora contaminadas. Sabe-se que não temos esse dom, que isso não é possível; no entanto, a simples leitura da peça, deixa o desejo de transformação, pois um governante pode ser ético e íntegro, abrindo mão de algo que deseje, o que outros, em seu lugar, não fariam.

\section{CONSIDERAÇÕES FINAIS}

As obras de Shakespeare ultrapassam os séculos, superando-os. Muitos são os estudos debruçados sobre elas, de modo que seus discursos são usados na arte, na literatura, na música, no cinema, no teatro, na televisão. Para um momento nem tanto absurdo, também é possível fazer uma leitura da Justiça (e da justiça) entre as suas obras, pois Shakespeare em muitos momentos mostrou-se capaz de antecipar acontecimentos históricos.

Até hoje, milhares de acadêmicos dedicam-se todos os dias, em vários cursos de ensino superior, em todos os países, a examinar seus escritos. É 
natural que Shakespeare entenda de Direito, pois ele entendia de diversos campos do saber; tendo, inclusive, o próprio Freud escrito sobre suas obras.

No Brasil e além-fronteiras, há várias experiências acadêmicas exitosas em torno das discussões sobre Direito e Literatura, como o programa de televisão que tem esse título, sob a batuta de Lenio Luiz Streck e André Karam Trindade.

A mensagem que fica é que o Direito é uma das ciências humanas e sociais mais antigas da humanidade, estando enraizada em qualquer indivíduo, independente de sua origem, raça, credo, gênero etc. $\mathrm{O}$ que a obra de Kenji Yoshino nos faz ver é que Shakespeare acentua, com maestria, que a justiça pode ocorrer de diversas formas: ao mostrar os extremos - da empatia e da letra fria da lei -, torna possível percebermos o quanto um equilíbrio na sua interpretação é de suma importância.

Submetido: 14/02/15

Aceito: 27/04/15 